\title{
CHILE, 40 AÑOS DE EXIGENCIAS DE VERDAD Y JUSTICIA
}

\author{
Boris $\mathrm{Hau}^{(a)}$
}

CHILE, 4O YEARS OF TRUTH AND JUSTICE DEMANDS

CHILE, 40 ANOS DE EXIGÊNCIAS DE VERDADE E JUSTIÇA

Fecha de recepción: 18 de septiembre del 2017

Fecha de aprobación: 5 de diciembre del 2017

\section{Sugerencia de citación:}

Hau, B. (2018). Chile, 40 años de exigencias de verdad y justicia. Razón Crítica, 4, 137-161, doi: http:// dx.doi.org/10.21789/25007807.1275

(a) Máster en Gobernanza y Derechos Humanos de la Universidad Autónoma de Madrid. Profesor del Observatorio Justicia Transicional de la Universidad Diego Portales, Santiago - Chile https:/ / orcid.org/0000-0003-4840-1092 borishau@yahoo.com 


\section{R E S U M E N}

Tras el regreso a la democracia en Chile, las políticas de justicia transicional iniciaron con la búsqueda de verdad, luego vinieron las políticas de reparación. Pero la justicia en Chile demoró en llegar: este proceso inició en 1998 con la interposición de la primera querella contra el exdictador Augusto Pinochet. En el año 2017 se cumplen 44 años del golpe militar, pero las consecuencias de las violaciones a los derechos humanos siguen estando vigentes. Cuatro décadas después, todavía se están investigando juicios de derechos humanos por el poder judicial. La Corte Suprema ha condenado a los principales responsables a penas de cárcel. En este trabajo se presenta el caso de Marcelo Concha, un joven militante comunista desaparecido en 1976. En 2016, sus familiares obtuvieron justicia al condenar la Corte Suprema a los responsables de este crimen, todos exagentes de la dictadura. Las políticas de verdad y justicia que se han realizado a 44 años de sucedidos los hechos son exigencia y requisito para una democracia consolidada que garantice un "nunca más" sobre esos hechos similares.

PALABRAS CLAVE: memoria, derechos humanos, justicia transicional, Chile, justicia. 


\section{A B S T R A C T}

After the return to democracy in Chile, the policies of Transitional Justice began with the search for Truth, and then with the Reparation policies. But justice in Chile was slow to arrive: this process began in 1998 with the filing of the first complaint against former dictator Augusto Pinochet. The year 2017 marks the 44th anniversary of the military coup, but the consequences of human rights violations continue to be matters of the present. After these four decades, human rights trials are being investigated by the judiciary power. The Supreme Court has sentenced the main perpetrators to jail terms. This paper presents the case of Marcelo Concha, a young Communist militant who disappeared in 1976. In 2016, his relatives obtained Justice after the Supreme Court condemned those responsible for this crime, all of them ex-agents of the dictatorship. The Truth and Justice policies that have been carried out 44 years after the events are a requirement and requisite for a consolidated democracy that guarantees a "never again" policy regarding similar events.

\section{KEY WORDS: memory, human rights, transitional justice, Chile, justice.}

\section{R E S U M O}

Após o retorno à democracia no Chile, as políticas da justiça de transição começaram com a busca da verdade; depois, vieram as políticas de reparação. Contudo, a justiça no Chile demorou em chegar, pois esse processo só começou a partir do ano de 1998, com a interposição da primeira denúncia contra o ex-ditador Augusto Pinochet. O ano de 2017 marca o $44^{\circ}$ aniversário do golpe militar, mas as consequências das violações dos direitos humanos ainda são importantes para o presente. Após quatro décadas do golpe militar, ainda os julgamentos sobre direitos humanos estão sendo investigados pelo Judiciário. O Supremo Tribunal condenou os principais culpados à prisão. Neste artigo, apresenta-se o caso de Marcelo Concha, um jovem militante comunista que desapareceu em 1976. Em 2016, seus familiares obtiveram justiça, quando o Supremo Tribunal condenou os responsáveis pelo crime, todos ex-agentes da ditadura. As políticas da verdade e da justiça, que foram feitas 44 anos após os eventos ocorridos, são exigência e requisito para uma democracia consolidada que garanta um "nunca mais" sobre fatos semelhantes.

PALAVRAS-CHAVE: memória, direitos humanos, justiça de transição, Chile, justiça. 


\section{N T R O D U C C I Ó N}

\section{Una familia exige justicia durante 40 años}

Tenía 30 años, estaba casado, tenía hijos pequeños, era ingeniero agrónomo y había estudiado en una universidad extranjera, también había tenido un alto cargo en la administración pública. Marcelo Concha vivió intensamente hasta que su existencia cambió drásticamente el 11 de septiembre de 1973, cuando un golpe militar derrumbó la democracia en Chile. Marcelo, como muchos otros chilenos, iba a ver alterados sus proyectos de vida. Estaba identificado por su militancia política, era miembro del Partido Comunista, había estudiado en la Unión Soviética, en la Universidad Patricio Lumbumba, en Moscú, y tenía un cargo en el Gobierno de la Unidad Popular. Esto llevó a que las autoridades de la dictadura lo detuvieran al día siguiente del golpe militar. Junto a cientos de personas estuvo detenido en el Estadio Nacional, un recinto deportivo convertido por la dictadura en un campo de concentración. Luego de meses de reclusión, fue enviado junto con otros prisioneros políticos a un recinto de detención, Chacabuco, en el desierto de Atacama en el norte de Chile. Fue libertado, se reencontró con su esposa, Aminta, y sus hijos.

Durante los siguientes tres años, los agentes de la Dirección de Inteligencia Nacional (en adelante DINA) iniciaron una persecución contra los militantes comunistas. Marcelo fue detenido el 10 de mayo de 1976, desde ese día su familia no tuvo noticias de él. Su esposa exigió ante los tribunales de justicia, a través de un recurso de amparo, una respuesta ante la detención de su marido, pero 
el poder judicial no le dio ninguna respuesta. Lo sucedido con Marcelo Concha fue parte de la represión contra los asociados a partidos de izquierda y exfuncionarios del gobierno depuesto. Durante los primeros años de la dictadura, muchos chilenos vivieron la prisión política y la tortura, fueron ejecutados, exiliados, detenidos o desaparecidos. Estos hechos configuran crímenes de lesa humanidad, definidos en el Estatuto de Roma y regido por la Corte Penal Internacional. En el artículo 7, numeral 1, dicho Estatuto señala cuáles actos son constitutivos de estos crímenes cuando estos sean parte de un ataque generalizado contra la población civil: asesinato, exterminio, esclavitud, deportación de población, encarcelación que viola normas de derecho, tortura, violación, violencia sexual, persecución de una colectividad, crimen de apartheid y la desaparición forzada de personas (Corte Penal Internacional, 1998, p. 7).

Luego de la dictadura de Pinochet y con el regreso de la democracia en 1990, los familiares de las víctimas (esposas, madres) exigieron al gobierno de la transición la materialización de políticas de verdad, reparación y justicia y los gobiernos democráticos fueron implementándolas, constituyendo las políticas de justicia de transición.

El Centro Internacional para la Justicia Transicional (en adelante ICTJ), ha definido a la justicia transicional como: "el conjunto de medidas judiciales y políticas que diversos países han utilizado como reparación por las violaciones masivas de derechos humanos. Entre ellas figuran las acciones penales, las comisiones de la verdad, los programas de reparación y diversas reformas institucionales" (ICTJ, s. f.).

Estas políticas buscan dar una repuesta a los crímenes sucedidos en un periodo dictatorial y deben alinearse con el derecho internacional y los derechos humanos, tal como lo advierten Roht-Arriaza y Bernabeu, que señalan que estos mecanismos de justicia de transición, implican "comisiones de verdad o programas de reparación para las víctimas y la creación y consolidación de instituciones de aplicación del derecho penal internacional" (2009, p. 294).

El proceso de justicia transicional en Chile fue paulatino: primero se realizaron las políticas de verdad y luego, las acciones de reparación. Pero la justicia no llegó en los primeros años, el 
Decreto-Ley de Amnistía y la permanencia del dictador Augusto Pinochet como jefe del ejército impidieron este proceso. Solo después de muchos años, los familiares de las víctimas de la dictadura obtuvieron justicia. Recién en el año 2016 los familiares de Marcelo Concha obtuvieron de parte de la corte suprema de Chile una sentencia judicial en la cual se relatan los hechos luego de su detención y se identificaron los culpables, todos ex agentes de la dictadura. Para llegar a esta sentencia final, la esposa e hijos de Marcelo tuvieron que exigir verdad, reparación y justicia durante cuarenta años.

La justicia transicional, tanto en las últimas décadas del siglo XX, como al principio del siglo XXI, ha implementado sus mecanismos para responder por las consecuencias de un periodo dictatorial. Sin embargo, estos mecanismos se han visto detenidos con el pretexto de "dejar atrás el pasado" y de un acuerdo social para realizar políticas sociales a futuro, pues remover el pasado $u$ ocuparse de hechos pasados afectaba la convivencia social.

Un orden social basado solo en las políticas de futuro aseguraría la paz social (Aguilar, 2008, p. 515). Esta es la realidad de España: luego de la muerte del dictador Franco, la clase política decidió no realizar revisiones de hechos pasados. Mecanismos de justicia transicional, como comisiones de verdad o juicios contra los responsables de las desapariciones y ejecuciones, han estado ausentes en España. Recién en el año 2007, 32 años después del fin del franquismo, a instancias del gobierno del socialista José Luis Rodríguez Zapatero, se promulgó la Ley 52/2007 o de Memoria Histórica. Una ley que tuvo por objetivo el asumir los hechos del pasado para realizar políticas de reparación. Es importante que la Ley reconoce en sus dos primeros artículos la existencia de fallecidos durante la Guerra Civil que nunca han sido reconocidos como víctimas por convicciones políticas (Ley de Memoria Histórica, 2007).

Amnistía Internacional, al evaluar la situación de los derechos humanos en España, exigió una respuesta a los crímenes del franquismo. Esto porque se impide "a las víctimas de graves violaciones de derechos humanos acceder a los tribunales españoles. En este sentido, y de manera adicional, los derechos a la verdad, la justicia y la reparación de las víctimas de crímenes de derecho internacional cometidos durante la Guerra Civil” 
(Amnistía Internacional, 2017). La Ley de Memoria Histórica ha sido un avance, pero ha quedado en el papel ya que no hay voluntad del Estado para avanzar con las identificaciones y establecer una política de reconocimiento oficial de estos crímenes. Hubo un intento de juzgar por parte del magistrado Baltazar Garzón, pero no logró materializarse. Persiste, por tanto, una deuda histórica con las víctimas, con sus familias, con sus nietos y bisnietos, que se resolvería con la realización de mecanismos de justicia transicional en España.

En Chile, la implementación de estas políticas de justicia transicional, como se verá en este trabajo, no fue un proceso exento de dificultades. Al regreso de la democracia en 1990 quién encabezó la dictadura siguió como jefe del ejército. A estos primeros años luego de la dictadura, Collins (2003, p. 84) los denomina "transición tutelada”, porque a pesar que gobernaba la Concertación, coalición de partidos de centro izquierda, el exdictador mantenía su poder; además, los parlamentarios de derecha impedían algún cambio real del legado dictatorial, como el Decreto-Ley de Amnistía. A esto debe sumarse una corte suprema que validaba la imposibilidad de realizar juicios por las víctimas de la dictadura. Pero a partir de 1998, con la detención de Pinochet, se iniciaría una nueva etapa en los mecanismos de justicia transicional.

\section{Un militante de izquierda es detenido, su familia exige justicia}

El 11 de septiembre de 1973 se produjo un quiebre institucional en Chile, cuando las Fuerzas Armadas derrocaron al gobierno elegido democráticamente. Una junta militar se tomó el poder y desde los primeros días iniciaron una represión contra los simpatizantes del derrocado gobierno. En las primeras semanas de la dictadura se produjeron numerosas detenciones de funcionarios públicos, así como de dirigentes sindicales, trabajadores, dirigentes estudiantiles y militantes de partidos de izquierda (Comisión Nacional de Verdad y Reconciliación, 1991, p. 101).

Marcelo Concha trabajaba para el Gobierno de la Unidad Popular, fue detenido el día 12 de septiembre para ser recluido en el Estadio Nacional. Ante la represión, surgió una respuesta 
para proteger los derechos humanos de los perseguidos. La Iglesia católica, junto a otras iglesias protestantes, crearon el Comité Pro Paz en octubre de 1973. En esta institución trabajaban asistentes sociales, religiosas y abogados. En los primeros días de atención recibieron las denuncias sobre detención o desaparición de personas. Se armó un equipo de abogados que interponía recursos de amparo ante los tribunales de justicia. En cada uno de estos recursos iba narrada la situación de detención del amparado y sus datos personales.

Según estadísticas publicadas en el Informe Rettig, el Comité Pro Paz prestó asesoría jurídica a 6994 casos de persecución política en la ciudad de Santiago (Comisión Nacional de Verdad y Reparación, 1991, p. 969). Luego del cierre del Estadio Nacional, Marcelo Concha fue trasladado junto a otros presos políticos a un campo de concentración en el desierto de Atacama, denominado Chacabuco. Su esposa, Aminta Traverso, realizó un viaje, organizado por el Comité Pro Paz, junto a otros familiares para visitar a los presos políticos. El 25 de abril de 1974 Marcelo fue liberado de Chacabuco, mientras muchos de sus compañeros de prisión partieron al exilio, él decidió quedarse en el país.

En 1975, el Comité Pro Paz se había consolidado como una institución de protección de los perseguidos por la dictadura, lo que llevó a que la dictadura forzara su disolución. El cardenal Raúl Silva recibió una carta firmada por el general Pinochet, quién le pidió cerrar el Comité Pro Paz. La dictadura no contaba que la Iglesia de Santiago no pararía el trabajo de defensa de los derechos humanos, por lo que se ordenó la creación de la Vicaría de la Solidaridad, que empezó su trabajo en enero de 1976 (Comisión Nacional de Verdad y Reparación, 1991, p. 969). La Vicaría continuó con el trabajo de interposición de recursos de amparo de parte de los abogados ante los tribunales. Según datos entregados por el Informe Rettig, entre la Vicaría de la Solidaridad y el Comité Pro Paz interpusieron cerca de 8700 recursos de amparo entre los años 1973 y 1988, de los cuales solo diez fueron acogidos. Con los recursos negados, el poder judicial cerraba las puertas para investigar el paradero de los detenidos desaparecidos (Comisión Nacional de Verdad y Reparación, 1991, p. 1273).

Marcelo Concha había retomado su actividad laboral luego de la prisión política. Trabajaba en una empresa particular, pero seguía 
participando en forma clandestina en el Partido Comunista, cuya directiva estaba actuando en secreto. En 1976, la DINA inició una represión contra los militantes comunistas. Marcelo fue detenido el día 10 de mayo de 1976 por sus agentes en la vía pública. Dos días después fue detenido el secretario general del Partido Comunista, Víctor Díaz López (Comisión Nacional de Verdad y Reparación, 1991, p. 1819).

El 12 de mayo de 1976 se interpuso ante la corte de apelaciones de Santiago un recurso de amparo por Marcelo Concha. Esta solicitud siguió el mismo resultado que los recursos interpuestos por la Vicaría de la Solidaridad: fue rechazada el 1 de junio y la Corte Suprema confirmó este rechazo el 7 de junio. El 15 de junio de 1976 se interpuso otro recurso de amparo por 42 personas detenidas desaparecidas. El 14 de julio de 1977 la cónyuge de Marcelo interpuso una querella en el $8^{\circ}$ juzgado del crimen de Santiago por el delito de secuestro en contra de los agentes de la DINA. La causa pasó, en 1979, a una investigación realizada por el ministro Servando Jordán por casos de detenidos desaparecidos. El proceso fue sobreseído temporalmente el 11 de abril de 1980. La causa avanzó sin realizar investigaciones. Por lo que, en 1989, el fiscal general militar solicitó la aplicación del Decreto-Ley 2191 de Amnistía. Esta solicitud fue acogida por el $2^{\circ}$ juzgado militar, que sobreseyó total y definitivamente la causa. La corte marcial confirmó el fallo en enero de 1992 (Memoria Viva, 2000). Todas estas acciones fueron impulsadas por Aminta, pero no estaba sola en esta lucha por exigir justicia: en la Vicaría de la Solidaridad se encontró con familiares de las víctimas de la dictadura que estaban en una situación similar a la suya. En las instalaciones de esta entidad se encontraban las oficinas de la Agrupación de Familiares de los Detenidos Desaparecidos (en adelante, AFDD), que empezó a funcionar a fines de 1974. Las mujeres de la AFDD entendieron que la búsqueda individual de sus familiares era infructuosa, por lo que juntas, motivadas por una lucha común de conocer el paradero de sus familiares detenidos, iniciaron protestas pacíficas como huelgas de hambre o protestas callejeras con el objetivo de dar a conocer a la opinión pública sus demandas de verdad y justicia (Comisión Nacional de Verdad y Reparación, 1991, p. 973). Aminta Traverso se incorporó a la agrupación para exigir conocer el paradero de Marcelo Concha. Pero está exigencia de los familiares no tuvo respuesta durante la 
dictadura. Su hija María Paz creció observando el activismo de su madre en la AFDD:

Que mi madre fuera miembro de la AFDD fue fundamental para entender su activismo por la búsqueda de justicia por el caso de mi padre, como por los demás desaparecidos. Esto significó que crecí con su ejemplo, siempre estuvo presente su lucha por la justicia. Por lo que su experiencia de ser miembro de la AFDD como luego en la ONG PIDEE ha sido un ejemplo para mí. Que mi madre sea una activista es parte de mi historia, por lo que siento una gran admiración por eso. (María Paz Concha, entrevista, 12 de septiembre de 2017).

\section{En democracia, la búsqueda de la verdad es una exigencia de la transición, pero la justicia deberá esperar}

Solo un día después del regreso a la democracia, el 12 de marzo de 1990, el presidente Patricio Aylwin pronunció un discurso en el Estadio Nacional, excentro de detención de presos políticos. Señaló que la búsqueda de verdad sobre las violaciones a los derechos humanos cometidas durante la dictadura era parte de las políticas que debía asumir el gobierno de la transición. El presidente señaló en su discurso que "la conciencia moral de la nación exige que se esclarezca la verdad respecto de los desaparecimientos de personas, de los crímenes horrendos y de otras graves violaciones a los derechos humanos ocurridas durante la dictadura" (Memoria Chilena, 2004).

Este primer gobierno debía enfrentar las "herencias" de la dictadura, como senadores y alcaldes designados. Además, tendría una particularidad: Augusto Pinochet no se retiró, sino que siguió como jefe del ejército, usando un resquicio legal, por lo que mantuvo su poder ahora vigilando al nuevo gobierno.

El tema de las violaciones a los derechos humanos cometidas durante la dictadura era un asunto que se debía resolver. Por eso, luego de algunos días de iniciada la democracia, el 25 de abril de 
1990, se creó la Comisión Nacional de Verdad y Reconciliación. Instaurar una comisión de la verdad al inicio de la democracia era parte de lo que el exmiembro de la Comisión Rettig, José Zalaquett, denominó "las políticas refundacionales para perfeccionar esta democracia”. Así, señaló: “una nación enfrenta el pasado de violaciones a los derechos humanos durante su época refundacional, tiene una importancia decisiva por la fuerza simbólica y la amplificación histórica que cobran los eventos que tienen lugar en tales períodos" (Zalaquett, 2000, 3). Estas políticas o la ausencia de ellas pueden dejar precedentes para toda la sociedad.

Al año siguiente, esta comisión entregó un informe que dio a conocer un listado de víctimas de la dictadura de Pinochet. Este informe solo incluyó personas ejecutadas o detenidos desaparecidos y el presidente Aylwin pidió perdón a los familiares de las víctimas. El Informe Rettig incluyó un listado de 1319 personas ejecutadas y 979 detenidos desaparecidos, para un total de víctimas no sobrevivientes de 2298 personas (Corporación Nacional de Reparación y Conciliación, 1996, p. 535). Familiares de Marcelo Concha dieron testimonio sobre su caso ante los funcionarios de la Comisión Rettig; además, presentaron antecedentes, como el recurso de amparo y las acciones judiciales interpuestas. La Comisión calificó su caso como el de un detenido desaparecido:

El 10 de mayo de 1976 fue detenido en el trayecto comprendido entre la casa de su madre y el Instituto de Fomento Pesquero, Marcelo Renán Concha Bascuñán, ex-funcionario del Servicio Agrícola y Ganadero (SAG) y de la CORFO, también militante del PC. Se le perdió el rastro a fines de abril de 1977 desde Villa Grimaldi.

La Comisión está convencida de que su desaparición fue obra de agentes del Estado, quienes violaron así sus derechos humanos. (Comisión Nacional de Verdad y Reparación, 1991, p. 819)

María Paz Concha reflexiona sobre el reconocimiento oficial de su padre como detenido desaparecido, que para ella tiene un significado social: "Es un signo importante que el Estado haga un reconocimiento de que esta persona está desaparecida, que esta persona fue víctima de violación a sus derechos humanos. 
Porque fue el mismo Estado que hace unos años antes causó esta desaparición de la persona” (María Paz Concha, entrevista, 12 de septiembre de 2017).

Luego del Informe Rettig surgieron acciones de reparación que emanaron de la Ley 19 123, como la entrega de una pensión a los familiares de las víctimas calificadas como tales por dicho informe (Biblioteca del Congreso Nacional de Chile, 1991).

Familiares de Marcelo Concha, su esposa e hijos fueron beneficiaros de estas pensiones. Además, son parte de un programa de salud, denominado PRAIS (Programa de Reparación y Atención Integral de Salud) y pudieron acceder a becas de educación. Estos beneficios sociales fueron solo para aquellos familiares de víctimas calificadas en el Informe Rettig (Observatorio de Justicia Transicional de la Universidad Diego Portales, 2015b).

La AFDD señaló que luego de conocer la verdad, se debía juzgar a los responsables de estos crímenes; además, exigían el fin del Decreto-Ley de Amnistía y, a través de su dirigente Sola Sierra, señalaron que se deben conocer los nombres de los responsables de estos crímenes y el paradero de los restos de los desaparecidos cuyos nombres están en el Informe Rettig (Camacho, 2008, p. 73). El exdictador Pinochet no aceptó el Informe Rettig. En una declaración, señaló que no aceptaban "las supuestas violaciones a los derechos humanos atribuidas al periodo 1973-1990" (Loveman y Lira, 2002, p. 85). Denunció además que repudiaba la campaña para culpar al ejército de tales hechos. Frente a la publicación del listado de víctimas del Informe, manifestó que "no aceptarían ser sentados en el banquillo de los acusados por haber salvado la libertad y la soberanía de la patria” (Loveman y Lira, 2002, p. 85).

Durante el gobierno de transición la justicia estuvo ausente. La dictadura dejó un Decreto-Ley de Amnistía que impedía la persecución penal de sus agentes de seguridad responsables de las violaciones a los derechos humanos. Además, la presencia de Pinochet como jefe del ejército les otorgaba seguridad a los exagentes de la represión que se mantenían como funcionarios del ejército. A pesar de todo esto, familiares de las víctimas exigieron justicia ante los tribunales.

Erika Hennings interpuso una querella por su marido Alfonso Chanfreau, detenido desaparecido en julio de 1974. Este caso fue investigado por una ministra hasta que los tribunales superiores 
exigieron el traspaso del proceso a la justicia militar. El motivo que causo preocupación fue que la ministra interrogó a exagentes de la dictadura que eran militares activos. La Corte Suprema, el 30 de octubre de 1992, ordenó el traspaso de toda la investigación que estaba realizando la ministra a la justicia militar para que este tribunal aplicara en definitiva el Decreto-Ley de Amnistía (Amnistía Internacional, 1992).

Esta postura de la corte suprema no era una novedad para el exabogado de la Vicaría de la Solidaridad, Roberto Garretón, quien advirtió que luego del regreso de la democracia en el poder judicial "absolutamente nada cambió. En términos generales, a pesar de la restauración democrática, las Cortes siguieron consagrando la impunidad" (Garretón, 2008, p. 8). Además, de acuerdo con la abogada Karinna Fernández, luego del regreso a la democracia y hasta 1998 los tribunales chilenos aplicaban de pleno derecho el Decreto-Ley de Amnistía, una vez que "se determinaba que el hecho denunciado revestía el carácter de delito perpetrado en el curso de los años determinados en dicho Decreto. Se trata de un periodo que se caracteriza por la oposición de los tribunales superiores a aplicar los preceptos legales y consuetudinarios de Derecho Internacional" (Fernández, 2010, p. 470).

Como un acto de reparación para los familiares de las víctimas de la dictadura, se creó en el año 1994 un Memorial del Detenido Desaparecido y Ejecutado en una gran muralla con los nombres de las víctimas de la dictadura. Este se ubicó en el Cementerio General de Santiago como un lugar de recuerdo y conmemoración, en especial para aquellas víctimas detenidas desparecidas. El nombre de Marcelo Concha está inscrito en este memorial junto a cientos de víctimas de la dictadura de Pinochet.

En el año 1994, asumió el presidente Eduardo Frei con una coalición de partidos de centro-izquierda. Pinochet también continuó como jefe del ejército. En este gobierno se mantuvieron las políticas de verdad, con una nueva instancia de reconocimiento de víctimas de la dictadura, presentadas en el Informe de la Corporación Nacional de Reparación y Reconciliación, en 1996. Este informe reconoció 899 nuevos casos, que corresponden a 776 personas ejecutadas y 123 detenidos desaparecidos. Esta cifra, sumada a las víctimas reconocidas en el Informe Rettig, arroja un total de 3197 víctimas de la dictadura, divididas en 2095 ejecutados 
políticos y 1102 detenidos desaparecidos (Corporación Nacional de Reparación y Reconciliación, 1996, p. 535).

En abril de 1997 se inauguró un sitio de memoria en el principal recinto de la DINA en la ciudad de Santiago. El excentro de detención de presos políticos, la Villa Grimaldi, fue transformado en un parque. El lugar donde estuvieron los presos políticos, donde se torturó y asesinó a cientos de personas, fue transformado en un sitio para conmemorar a todas las víctimas que estuvieron en ese recinto (Villa Grimaldi, 2017). Fue en este lugar donde la DINA mantuvo detenido a Marcelo Concha y, según prueba testimonial, es desde ese lugar donde se pierde su paradero. A falta de una tumba, sus hijos y su esposa pueden realizar ritos de conmemoración de Marcelo en este recinto.

\section{Luego de años de impunidad, se obtiene justicia}

La dirigente del partido comunista de Chile, Gladys Marín, interpuso el 13 de enero de 1998 una querella criminal contra el exdictador Augusto Pinochet, quien ostentaba en esa fecha el cargo de jefe del ejército. La acción judicial era por un grupo de militantes comunistas desaparecidos en 1976. Los tribunales aceptaron la querella designado al ministro Juan Guzmán, quien se encargaría de investigar a Pinochet. Ocho años después del inicio de la democracia, la palabra justicia estaba ausente para las víctimas de la dictadura (Loveman y Lira, 2002, p. 207). Los familiares de las víctimas habían recibido acciones de reparación que emanaron de las comisiones de verdad, pero no justicia. Con la interposición de la primera querella contra Augusto Pinochet por los crímenes cometidos durante la dictadura, la muralla de la impunidad empezaría a resquebrajarse.

También en España se interpuso una querella contra Augusto Pinochet con la intención de hacer justicia por los españoles víctimas de violaciones a los derechos humanos durante la dictadura chilena y fue aceptada por el magistrado Baltasar Garzón. El exdictador dejó de ser jefe máximo del ejército en marzo de 1998, luego de haber estado 24 años en esa posición. Al dejar la jefatura del ejército, Pinochet no pretendía dejar el poder. Al día siguiente 
prestó juramento como senador vitalicio. Una vez más, ocupaba un cargo impuesto por la constitución que él ordenó redactar. En la ceremonia en la cual prestó juramento como senador, los senadores de la coalición gobernante le mostraron con carteles los rostros de las víctimas de la dictadura. Augusto Pinochet no se inmutó ante esta protesta, pues estaba rodeado por senadores designados y senadores de los partidos de derecha (Loveman y Lira, 2002, p. 194).

Solo unos meses después, el 16 de octubre de 1998, Pinochet viajó a Londres y mientras estaba convaleciente en una clínica, oficiales de la policía de Londres le leyeron una orden de detención. Pinochet estaba oficialmente detenido por solicitud del magistrado Baltazar Garzón, quien solicitaba se iniciara un proceso de extradición a España. Por primera vez, Pinochet era detenido por crímenes de derechos humanos cometidos durante su dictadura (Garzón, 2016, p. 262).

Para Roberto Garretón "Chile cambió el 16 de octubre de 1998”, el día de la detención de Pinochet en Londres, porque este fue acusado por la justicia española de crímenes de lesa humanidad, por genocidio, torturas y terrorismo de Estado. Para Garretón, la detención de Pinochet destruyó lo que era un discurso oficial desde el Estado: que luego del Informe Rettig, luego de conocer la verdad, Chile avanzaba bien, que era un país reconciliado con el pasado. La detención de Pinochet demostró que eso era una ilusión, que quedaban temas pendientes. La denominada reconciliación nacional era solo un discurso del gobierno: los familiares de las víctimas no olvidaban que obtuvieron una verdad sin justicia. Por ello, luego de la detención, el tema de las violaciones a los derechos humanos que se cometieron en la dictadura volvió a ser de interés público (Garretón, 2009, p. 79).

Se inició un proceso de extradición a España para que el exdictador respondiera por los crímenes por los cuales estaba siendo acusado. Chile solicitó a Inglaterra la expulsión de Pinochet, luego de comprobar que el proceso de extradición avanzaba. El gobierno apelaba a "razones de Estado", argumentando la soberanía de los países para juzgar a sus nacionales. Finalmente, Pinochet fue expulsado de Inglaterra, el 3 de marzo del 2000, por razones humanitarias (Garretón, 2009, p. 79). En Chile lo esperaban las querellas e investigaciones por casos de derechos humanos. En el aeropuerto, después de meses de ser visto en silla de ruedas, el 
exdictador se levantó y caminó saludando a los militares que lo recibían, entre los que se encontraba el jefe del ejército (Loveman y Lira, 2002, p. 294).

Mientras Pinochet estaba en Londres, los familiares de las víctimas de la dictadura interpusieron querellas en su contra. Collins explica que "las causas en este entonces fueron, sin excepción, producto de querellas privadas realizadas por familiares y sobrevivientes, muchas de ellas reactivando además causas existentes que habían estado adormecidas o sobreseídas dentro de la justicia militar" (Collins, 2013, p. 99).

El 11 de marzo del 2000 se inició el gobierno de Ricardo Lagos, el primer presidente socialista luego de Salvador Allende. Este gobierno se hizo cargo de una instancia de negociación de representantes del gobierno, junto con académicos, líderes religiosos y representantes de las Fuerzas Armadas. Dicha instancia se denominó Mesa de Diálogo y su objetivo era recibir información de parte de las Fuerzas Armadas de los sitios donde se enterraron los detenidos desaparecidos. Los miembros de esta Mesa de Diálogo emitieron una declaración final en la cual, por primera vez desde el regreso a la democracia, las Fuerzas Armadas reconocieron que durante la dictadura se cometieron violaciones a los derechos humanos. En la declaración se señaló: "nos preocupa hondamente la tragedia, aún no resuelta, de los detenidos desaparecidos. Es imperativo y urgente contribuir a superar este problema. Ello requiere, de parte de todos, un espíritu de grandeza moral que nos permita concordar medidas efectivas para ese fin" (Mesa de Diálogo, 2000).

Las Fuerzas Armadas tomaron el compromiso de entregar información sobre los lugares donde se encontraban enterrados los detenidos desaparecidos. Esta información fue entregada al presidente Lagos, en muchos casos los militares reconocieron que los detenidos fueron lanzados al mar. En el informe presentado por las Fuerzas Armadas, se nombró a Marcelo Concha como uno de los detenidos lanzado al mar. Hubo pues un reconocimiento de que se hizo desaparecer su cuerpo lanzándolo frente a San Antonio, puerto situado cerca de Santiago (Fuerzas Armadas de Chile, 2000).

Uno de los resultados de la Mesa de Diálogo fue la solicitud al poder judicial de nombrar magistrados para investigar los casos 
de derechos humanos. Este respondió nombrando ministros para investigar casos en todo el país (Garretón, 2009, p. 80). Los ministros contaron con la colaboración de la Policía de Investigaciones, que creó una Brigada de Derechos Humanos para investigar estos casos. El Servicio Médico Legal instauró un departamento especial forense para dar respuesta.

El primer caso de un detenido desaparecido en el que se hizo justicia fue el de Miguel Ángel Sandoval, militante del Movimiento de Izquierda Revolucionario (en adelante MIR), detenido desaparecido en el año 1975. El ministro Alejandro Solís, quien investigó el caso, en su sentencia estableció la tesis de secuestro permanente de la víctima, por lo que su sentencia rechazó aplicar la prescripción y la amnistía. En esta sentencia se condenó a prisión a exagentes de la DINA. La corte suprema respaldó esta tesis jurídica en una sentencia dictada el 17 de noviembre del año 2004 (Observatorio de Justicia Transicional de la Universidad Diego Portales, 2015a).

Desde la sentencia en el caso Miguel Ángel Sandoval, se ha aplicado la tesis de secuestro permanente, por lo que los exagentes de la DINA han seguido ingresando al penal de Punta Peuco. Según Garretón, con esta sentencia, que marca un precedente jurisprudencial de hacer justicia en un caso de un detenido desparecido, los jueces "perdieron el miedo a hacer justicia" (Garretón, 2009, p. 98).

En septiembre del 2003, al recordarse los 30 años del golpe militar, el presidente Ricardo Lagos hizo una propuesta que denominó "No hay mañana sin ayer", donde planteó una serie de medidas para avanzar en las políticas de derechos humanos y asumir la violación de los mismos. En el discurso de presentación de este proyecto, hizo un recuerdo de todas las medidas de verdad y reparación que se habían realizado en beneficio de los familiares de las víctimas y recordó que:

Es deber de todos los chilenos, y en especial mi deber como jefe de Estado, impulsar con convicción medidas que contribuyan a legar a las nuevas generaciones una nación cuya alma esté unida y en paz, y cuya conciencia moral haya dado los pasos necesarios en verdad, justicia y reparación. (Lagos, 2003). 
Entre estas medidas estaba el apoyo desde el Estado para la construcción de memoriales en todo el país que recuerden a las víctimas de la dictadura. Lagos ordenó la creación de una nueva comisión de verdad, la Comisión Valech, cuyo objetivo fue recibir los testimonios de personas que vivieron la prisión política y la tortura durante la dictadura. En noviembre del 2004, el presidente Lagos dio a conocer que el Informe Valech, sustentado en testimonios de las víctimas en Chile y el extranjero. Este informe estableció que 27255 personas fueron víctimas de prisión política, a los que se sumaron los casos de un periodo de reconsideración, en el que fueron calificados 1204 casos (Comisión Nacional sobre Prisión Política y Tortura, 2004, p. 81). El total de personas calificadas por la Comisión Valech fue entonces de 28459 personas. Luego de este informe surgió la Ley 19 992, que entregó políticas de reparación para las víctimas sobrevivientes de la dictadura (Biblioteca del Congreso Nacional de Chile, 2004).

En marzo de 2006, Michelle Bachelet se convirtió en la primera mujer presidenta de Chile. Para Bachelet, el tema de las violaciones a los derechos humanos cometidas durante la dictadura no era ajeno: era parte de su historia familiar, y ella misma fue presa política. Su padre, un general de la aviación, falleció producto de las torturas que recibió de parte de sus excompañeros. La primera vez que un presidente visitó el sitio de Memoria Villa Grimaldi fue cuando Michelle Bachelet regresó al lugar donde estuvo detenida junto a su madre en la dictadura.

El 26 de septiembre del año 2006, la Corte Interamericana de Derechos Humanos $(\mathrm{CoIDH})$ condenó a Chile por el caso del profesor Luis Almonacid, exigiendo al Estado la anulación del Decreto-Ley de Amnistía, así como que los tribunales se abstuvieran de su aplicación por ser contraria a la Convención Americana de Derechos Humanos. La Corte señaló que "el Estado debe asegurarse que el Decreto-Ley No. 2.191 no siga representando un obstáculo para la investigación, juzgamiento y, en su caso, sanción de los responsables de otras violaciones similares acontecidas en Chile” (CoIDH, 2006, p. 65). Además, se exigió hacer justicia en casos de violaciones a los derechos humanos: "la Corte estima que los Estados no pueden sustraerse del deber de investigar, determinar y sancionar a los responsables de los crímenes de lesa humanidad aplicando leyes de amnistía u otro tipo de normativa 
interna. Consecuentemente, los crímenes de lesa humanidad son delitos por los que no se puede conceder amnistía” (Corte Interamericana de Derechos Humanos, 2006, p. 50).

El caso tuvo origen en la lucha contra la impunidad que realizó Elvira Gómez viuda del profesor Luis Almonacid al exigir justicia por la muerte de su marido ejecutado fuera de su domicilio en 1973. Ella interpuso una querella ante los tribunales de justicia y estos aplicaron el Decreto-Ley de Amnistía para no investigar el caso. Ante esta muestra de impunidad de parte de los tribunales, demandó a Chile ante la Corte, fallando está en contra del Estado.

Luego de la sentencia del profesor Almonacid, desde septiembre de 2006, el poder judicial se ha abstenido de la aplicación de este Decreto en casos de víctimas de la dictadura. La primera vez que se aplicó esta nueva jurisprudencia fue unos meses después de la sentencia de la Corte: en diciembre de 2006 en el caso Hugo Vásquez y Mario Superby, ambos ejecutados políticos, se aceptó la calificación de crimen de lesa humanidad y se fundamentó la sentencia invocando el fallo del caso Almonacid de la $\mathrm{CoIDH}$ (Observatorio de Justicia Transicional de la Universidad Diego Portales, 2015a).

Se ha aplicado esta nueva jurisprudencia en las querellas interpuestas por víctimas sobrevivientes, en casos de tortura y para el pago de indemnización de parte del Estado para las víctimas. En esta nueva jurisprudencia, tanto la corte suprema, como los demás tribunales han establecido que en los casos de derechos humanos no es posible la aplicación de la prescripción ni del Decreto-Ley de Amnistía. Esta jurisprudencia se ha mantenido sin cambios.

El 10 de diciembre del 2006, día de los derechos humanos, murió Pinochet. Antes de fallecer estaba siendo investigado en una gran cantidad de juicios por violación de los DD. HH. Durante el gobierno de Bachelet se creó una nueva comisión de verdad, la Comisión Asesora Presidencial para la Calificación de Detenidos Desaparecidos, Ejecutados Políticos y Víctimas de Prisión Política y Tortura, conocida como la Comisión Valech II, cuyo informe se hizo público el 2011. En este informe se calificaron treinta nuevos casos de víctimas no sobrevivientes, que sumados a las cifras de las comisiones anteriores arrojaron un total de 3218 personas desaparecidas o ejecutadas. En el caso de las personas que sufrieron la prisión política y la tortura, en la Comisión Valech II se sumaron 
9795 casos, dando un total de 38254 entre ambas comisiones (Observatorio de Justicia Transicional de la Universidad Diego Portales, 2015c).

El gobierno de Bachelet impulsó la construcción de un Museo de la Memoria, un lugar para rendir homenaje a las víctimas de los crímenes de derechos humanos y conservar documentos y objetos del tiempo de la dictadura. El 11 de enero del año 2010 la presidenta inauguró el Museo de la Memoria y los Derechos Humanos, en su discurso hizo un llamado a un compromiso para que nunca más se repitan estos hechos:

La inauguración de este Museo es una poderosa señal del vigor de un país unido. Unión que se funda en el compromiso compartido de nunca más volver a sufrir una tragedia como la que en este lugar siempre recordaremos, tragedia que desde el primer día sumó la negación y el ocultamiento al dolor del cautiverio o la muerte. (Museo de la Memoria y los Derechos Humanos, 2010)

Marcelo Concha es uno de los cientos de rostros que están presentes en antiguas fotografías en una muralla del Museo de la Memoria.

En 1976, la esposa de Marcelo Concha interpuso un recurso de amparo ante los tribunales exigiendo saber el paradero de su marido, pero no obtuvo respuesta. Cuarenta años después son los hijos de Marcelo los que asumieron el rol de buscar justicia por su padre detenido desaparecido, en concordancia con lo planteado por Hirsch, quien señala que las historias, los testimonios de violaciones a los derechos humanos, se transmiten en las familias de padres a hijos, pues los hijos de los sobrevivientes o de las víctimas viven marcados por las experiencias, por las emociones transmitidas (2015, p. 59). Por ello, los hijos de Marcelo Concha interpusieron la querella en esta nueva etapa, declararon ante el magistrado y estuvieron presentes en los alegatos en las cortes superiores de justicia.

En 2016, la familia de Marcelo Concha obtuvo una sentencia final de parte de la corte suprema. Luego de cuatro décadas, sus hijos supieron quiénes fueron los autores de la detención y desaparición de su padre. El proceso judicial fue adelantado por uno 
de los ministros designados para investigar casos de violaciones a los derechos humanos de la dictadura, el ministro Leopoldo Llanos. El 2 de septiembre del 2015 la justicia chilena condenó a los exagentes de la DINA Pedro Espinoza Bravo, Carlos López Tapia, Rolf Wenderoth Pozo, Ricardo Lawrence Mires y Juan Morales Salgado a penas de diez años y un día de prisión como autores del delito de secuestro calificado. La sentencia señaló que luego de su detención, Marcelo Concha estuvo recluido en Villa Grimaldi y el cuartel Simón Bolívar (Poder Judicial, 2015). El caso fue apelado, pero el 9 de junio del 2016 se confirmaron las penas (Poder Judicial, 2016a).

La Corte Suprema dictó sentencia definitiva el 25 de octubre de 2016, ratificando el fallo del magistrado Leopoldo Llanos; además, revocó la decisión de segunda instancia de absolver al agente Rolf Wenderoth, por lo que quedaron en firme las condenas de diez años y un día para los exagentes de la DINA involucrados (Poder Judicial, 2016b).

Para María Paz Concha, la condena definitiva contra los culpables de la detención y desaparición de su padre cierra un proceso largo de exigencia de justicia:

Cuando se cierra el proceso con la sentencia final, con las condenas, se cierra un ciclo personal. Pero en la práctica no se cierra, porque quieres que también exista justicia en otros casos, para otras personas. Entonces el tema de exigir justicia sigue presente en otros casos. Porque tú esperas lo mismo que uno obtuvo, que es justicia para vencer la impunidad. (María Paz Concha, entrevista, 12 de septiembre de 2017)

Los juicios de derechos humanos para las víctimas de la dictadura siguen siendo investigados en los tribunales en Chile. Según datos del Observatorio de Justicia de Transición de la Universidad Diego Portales, de un total de 55 sentencias falladas en la Corte Suprema, entre julio del 2016 y junio del 2017, por casos de violaciones a los derechos humanos durante la dictadura, solo seis son de responsabilidades civiles, mientras los restantes 49 trataron sobre causas penales (Observatorio de Justicia Transicional de la Universidad Diego Portales, 2017, p. 68), lo que demuestra la insistencia de las víctimas para que se castigue a los culpables, más allá de la reparación. 


\section{Conclusión. Chile, políticas de verdad y justicia para asegurar un nunca más}

40 años después de la detención de Marcelo Concha, su familia obtuvo respuesta de parte de los tribunales chilenos. Una lucha que inició su esposa Aminta en 1976 y que heredaron sus hijos, cumpliendo lo que Hirsch (2015) denominó la generación de la posmemoria: una generación que crece recibiendo el relato y los testimonios de aquellos que fueron víctimas de las violaciones de los derechos humanos.

Para Hirsch (2015), es una asimilación de los relatos de una generación a otra. La "generación bisagra", como denomina la autora a la generación descendiente de aquella que vivió o fue testigo de violaciones a los derechos humanos, asume una "custodia de este pasado", transformándose en una "conexión viva” de esta herencia (p. 13).

En el caso de Marcelo Concha, la "generación bisagra" fue conformada por sus hijos, que crecieron junto a una madre activista que les inculcó el deber de buscar justicia. Los hijos asumieron esta tarea interponiendo nuevamente querellas. Pero el relato de estos hijos es el relato de hechos traumáticos, lo que implica que las nuevas generaciones deben asimilar estos hechos como parte de su propia historia (Hirsch, 2015, p. 59).

El caso de Marcelo Concha pasa ser parte de la memoria del conjunto de familias que en Chile han exigido verdad y justicia, estas "memorias" se suman para conformar una memoria colectiva, tal como lo señala Jellin (2002): "Las memorias son simultáneamente individuales y sociales, ya que en la medida en que las palabras y la comunidad del discurso son colectivas, la experiencia también lo es" (p. 37).

En Chile se están sumando historias de familias que han luchado durante años exigiendo verdad y justicia para sus familiares, pero tal como lo señaló María Paz Concha en su testimonio para este trabajo, una vez que una familia logra justicia, se da cuenta de que hay otras familias que todavía esperan justicia, pues para algunas pasan los años sin que una sentencia judicial cierre sus procesos personales, sin que los tribunales sancionen a los culpables. 
Es por lo anterior que la exigencia de justicia para las víctimas de la dictadura sigue presente en Chile. Los tribunales han respondido a las exigencias de justicia con magistrados que han investigado estos casos y dictado sentencias por crímenes de lesa humanidad. Estas sentencias son parte, junto con las comisiones de verdad y las acciones de reparación, de las políticas de justicia de transición. La realización de este proceso debería garantizar que estos dolorosos hechos nunca más vuelvan a ocurrir.

\section{Referencias}

Aguilar, P. (2008). Políticas de la Memoria y Memorias de la Política. Madrid: Alianza Editorial.

Amnistía Internacional (2017). La lucha contra la impunidad en España. Recuperado de https://www.es.amnesty.org/en-que-estamos/espana/ lucha-contra-la-impunidad/

Amnistía Internacional (1992). Chile: La Corte Suprema de justicia continúa bloqueando las investigaciones sobre pasadas violaciones de derechos humanos: El Caso Chanfreau. Recuperado de https://www.amnesty.org/es/documents/amr22/017/1992/es/

Biblioteca del Congreso Nacional de Chile (1991). Ley 19.123. Recuperado de http://bcn.cl/1vuwr

Biblioteca del Congreso Nacional de Chile (2004). Ley 19.992. Recuperado de http://bcn.cl/luw0h

Bernabeu, A., y Roht-Arriaza, N. (2009). Justicia transnacional como un proceso híbrido. En J. Almqvist, y C. Espósito (coords.), Justicia transicional en Iberoamérica. Madrid: Editorial Centro de Estudios Políticos y Constitucionales.

Camacho, F. (2008). Memorias enfrentadas: las reacciones a los informes Nunca Más de Argentina y Chile. Recuperado de http://www.archivochile.com/Ideas_Autores/camachopf/ camachopf0004.pdf

Collins, C. (2013). Chile a más de dos décadas de justicia de transición. Revista de Ciencia Política, 51(2). Recuperado de http://www.revistapolitica.uchile.cl/index.php/RP/article/ view/30160/32102

Comisión Nacional de Prisión Política y Tortura (2004). Informe de Comisión Nacional de Prisión Política o Tortura. Recuperado de http:// bibliotecadigital.indh.cl/handle/123456789/455

Comisión Nacional de Verdad y Reconciliación (1991). Informe de la Comisión Nacional de Verdad y Reconciliación. Recuperado de http:// bibliotecadigital.indh.cl/handle/123456789/170 
Concha, M. P. entrevista el 12 de septiembre de 2017.

Corporación Nacional de Reparación y Reconciliación (1996). Informe de la Corporación Nacional de Reparación y Reconciliación. Disponible en: http://pdh.minjusticia.gob.cl/comisiones/

Corte Interamericana de Derechos Humanos (2006). Caso Almonacid Arellano y otros Vs. Chile. Recuperado de http://www.corteidh.or.cr/ docs/casos/articulos/seriec_154_esp.pdf

Corte Penal Internacional (1998). Estatuto de Roma. Recuperado de http:// www.un.org/spanish/law/icc/statute/spanish/rome_statute(s).pdf

Fernández, K. (2010). Breve análisis de la jurisprudencia chilena, en relación a las graves violaciones a los derechos humanos cometidos durante la dictadura militar. Estudios constitucionales, 8(1), doi: https://dx.doi.org/10.4067/S0718-52002010000100018

Fuerzas Armadas de Chile (2001). Listado de víctimas de detención y desaparición entregado por las Fuerzas Armadas según los Acuerdos de la Mesa de Diálogo, 8 enero 2001. Recuperado de http://www.archivochile. com/Derechos_humanos/M_Dialogo/gob/hhddmdgob0001.pdf

Garretón, R. (2009). Los tribunales con jurisdicción penal durante la transición a la democracia en Chile. En J. Almqvist, y C. Espósito (coords.), Justicia transicional en Iberoamérica. Madrid: Editorial Centro de Estudios Políticos y Constitucionales. Garretón, R. (2008). Los tribunales con jurisdicción penal durante la transición a la democracia en Chile. Recuperado de http://www.auschwitzinstitute. org/wp-content/uploads/2015/05/m25aNaturaleza-de-dictaduraChile.-Rol-de-Poder-judicial.pdf

Garzón, B. (2016). En el punto de mira. Madrid: Editorial Planeta.

Hirsch, M. (2015). La generación de la posmemoria. Escritura y cultura visual después del Holocausto. Madrid: Editorial Carpe Noctem.

Jelin, E. (2002). Los trabajos de la Memoria. Madrid: Editorial Siglo XXI.

ICTJ (s. f.). ¿Qué es la Justicia Transicional? Recuperado de https://www.ictj. org/es/que-es-la-justicia-transicional

Loveman, B., y Lira, E. (2002). El espejismo de la reconciliación política: Chile 1990-2002. Santiago: Editorial Lom.

Memoria Chilena (2004). Discurso del Presidente de la República don Patricio Aylwin, Estadio Nacional, 12 de marzo de 1990. Recuperado de http://www.memoriachilena.cl/archivos2/pdfs/MC0059503.pdf.

Memoria Viva (2000). Caso Marcelo Concha. Recuperado de http://www. memoriaviva.com/Desaparecidos/D-C/con-bas.htm

Mesa de Diálogo. (2000). Declaración final. Recuperado de http://pdh. minjusticia.gob.cl/wp-content/uploads/2015/12/Declaracion_ Acuerdo_Final.pdf

Ministerio de Justicia (2007). Ley de la Memoria Histórica: Ley 52/2007 de 26 de diciembre de 2007. Recuperado de http://leymemoria.mjusticia.gob.es/ cs/Satellite/LeyMemoria/es/memoria-historica-522007 
Museo de la Memoria y los Derechos Humanos (2010). Discurso de

Michelle Bachelet. 11 de enero de 2010. Recuperado de http://ww3. museodelamemoria.cl/wp-content/uploads/2016/01/discursopresidenta.pdf

Lagos, R (2004). No hay mañana sin ayer. Recuperado de http://

bibliotecadigital.indh.cl/bitstream/handle/123456789/183/no-haymanana.pdf? sequence $=1$

Observatorio de Justicia Transicional de la Universidad Diego Portales (2017). Informe Anual sobre Derechos Humanos en Chile 2017. Recuperado de http://www.derechoshumanos.udp.cl/derechoshumanos/index. php/informe-ddhh-2017

Observatorio de Justicia Transicional de la Universidad Diego Portales (2015a). Principales hitos Jurisprudenciales en causas DDHH en Chile 19902015. Recuperado de http://www.derechoshumanos.udp.cl

Observatorio de Justicia Transicional de la Universidad Diego Portales (2015b). Tabla leyes y medidas de reparación en Chile. Recuperado de http://www.derechoshumanos.udp.cl

Observatorio de Justicia Transicional de la Universidad Diego Portales (2015c). Cifras de víctimas y sobrevivientes de violaciones masivas a los ddhh oficialmente reconocidas por el Estado chileno. Recuperado de http://www. derechoshumanos.udp.cl

Poder Judicial (2015). Ministro Leopoldo Llanos condena a 5 agentes de la DINA por el secuestro de Marcelo Concha Bascuñán. Recuperado de http://www.pjud.cl/web/guest/noticias-del-poder-judicial/-/ asset_publisher/kV6Vdm3zNEWt/content/ministro-leopoldo-llanoscondena-a-5-agentes-de-la-dina-por-el-secuestro-de-marcelo-conchabascunan

Poder Judicial (2016a). Corte de Santiago dicta sentencia en tres casos de violación a los derechos humanos. Recuperado de http://www. pjud.cl/web/guest/noticias-del-poder-judicial/-/asset_publisher/ kV6Vdm3zNEWt/content/corte-de-santiago-dicta-sentencia-en-trescasos-de-violacion-a-los-derechos-humanos

Poder Judicial (2016b). Corte Suprema condena a agente de la DINA a 10 años y un día de presidio por el secuestro calificado de ingeniero agrónomo. Recuperado de http://www.pjud.cl/web/guest/noticiasdel-poder-judicial/-/asset_publisher/kV6Vdm3zNEWt/content/cortesuprema-condena-a-agente-de-la-dina-a-10-anos-y-un-dia-de-presidiopor-el-secuestro-calificado-de-ingeniero-agronomo Villa Grimaldi. Recuperación de Villa Grimaldi. Recuperado de http://villagrimaldi.cl/ historia/recuperacion-de-villa-grimaldi/

Zalaquett, J. La mesa de diálogo sobre derechos humanos y el proceso de transición politica en Chile. Recuperado de http://www.indh.cl/wp-content/ uploads/2010/10/Mesa_de-Dialogo_CEP2000.pdf 